Article

\title{
Productivity and Income Effect of Breast Cancer among Women in Southwestern Nigeria
}

\author{
Josue Mbonigaba and Wilfred Gbenga Akinola *
}

check for updates

Citation: Mbonigaba, Josue, and Wilfred Gbenga Akinola. 2021. Productivity and Income Effect of Breast Cancer among Women in Southwestern Nigeria. Economies 9: 129. https://doi.org/10.3390/ economies 9030129

Academic Editor: Edward C. Hoang

Received: 24 December 2020

Accepted: 22 July 2021

Published: 8 September 2021

Publisher's Note: MDPI stays neutral with regard to jurisdictional claims in published maps and institutional affiliations.

Copyright: (c) 2021 by the authors. Licensee MDPI, Basel, Switzerland. This article is an open access article distributed under the terms and conditions of the Creative Commons Attribution (CC BY) license (https:/ / creativecommons.org/licenses/by/ $4.0 /)$.
School of Accounting, Economics and Finance, College of Law and Management, University of KwaZulu-Natal, Westville Campus, Durban 4000, South Africa; mbonigaba@ukzn.ac.za

* Correspondence: akinolag@ukzn.ac.za; Tel.: +27-788-682-356

\begin{abstract}
Women's breast cancer (BC) in Africa is detrimental to development, given the role women play in their families and society's well-being. Policymakers should be alerted to the effects of BC. This paper describes the income impact of breast cancer and assesses factors that influence income and productivity among women with BC. Cross-sectional data were collected using questionnaires on 200 women with clinically confirmed BC cases in Southwest Nigeria over 6 months. About sixty-one percent $(61.5 \%)$ of the women with clinically confirmed BC cases were self-employed, $62 \%$ were absent at the workplace for 7 days, indicating that $31.8 \%$ suffered productivity loss at the workplace on average. Sixteen percent of women in the group were absent at the workplace for an average of 10 days, showing a $45.5 \%$ productivity loss at the workplace. Lastly, $22 \%$ of the women were absent at the workplace for more than 2 weeks on average. An increasing incidence of BC among women causes a $26.2 \%$ decrease in productivity level at the workplace. The results from simple linear regression corroborate the findings from the descriptive statistics that $\mathrm{BC}$ has a significant but inverse effect on women's income and productivity. It showed that an increase in the number of confirmed cases of BC will decrease economic impact and productivity by $13.5 \%$ and $19.5 \%$, respectively. These findings urgently call for the attention of the policymakers.
\end{abstract}

Keywords: women; breast cancer; productivity effect; income effects

JEL Classification: I1; I12; I11

\section{Introduction}

Breast cancer is a health issue that is detrimental to women's health and economic outcomes due to its high mortality (Azubuike et al. 2018). Research shows that women with breast cancer are less productive, mainly due to the loss of labor-hours due to personal illness (Garau et al. 2015). Productivity loss can also arise from side effects of treatment or premature mortality from breast cancer. Breast cancer is likely to worsen women's economic outcomes as they are already part of the vulnerable groups and, by extension, to the entire economy.

Studies on BC have highlighted the significant and economic impact of BC due to sickness or death. In the United States of America, Trogdon et al. (2020) analyzed productivity loss among younger (18-44 years old), midlife (45-64 years), and older women ( $\geq 65$ years). Productivity loss was measured in terms of the productively lost time due to metastatic breast cancer (MBC). The study used the National Vital Statistics System data over 2000-2016 and estimated the number of home and work productivity days lost. The value of productive lost days per woman ranged from USD 680 for older women to USD 5169 for younger women (Slater 2020). Another study in this country (Ekwueme et al. 2014) used United States mortality data on mortality over time to estimate the value of potential years of life lost using Join point regression modeling. The study found that the loss of productivity in 2008 was USD 5.49 billion, and individual lifetime lost earnings were USD 1.10 million. 
In Africa, a recent review of the $\mathrm{BC}$ developmental effect highlighted that Africa currently had the highest age-standardized BC mortality, with the highest incidence rates recorded within the sub-Saharan Africa (Azubuike et al. 2018). The study concluded that BC would compound sub-Saharan Africa's disease burden, increase poverty, gender inequality, and maternal and neonatal mortality. In Nigeria, women are most likely to suffer a lot due to this situation. A recent study showed that these women are marginalized and do not partake in formal economic activities (De-Silva 2016). Another study showed that women in Africa, where Nigeria is located, are involved in informal activities for survival where their productivity and incomes are lower. Breast cancer only compounds the situation. The evidence to date in Nigeria suggests an age-standardized incidence of cancer rate to be higher among females than males (Jedy-Agba et al. 2012). The breast cancer age-standardized rate (ASR) incidence ranged from 52.0 per 100,000 to 100,000 in Nigeria (Jedy-Agba et al. 2012). While it is expected that these health effects will impact on women's participation in productive activity, the evidence in this respect remains limited. In particular, the impact of cancer in the context of marginalization in the economy has not been presented. The loss of productivity amongst the women in Nigeria can be expected from the diseases' health effects on these women. Breast cancer among women in Nigeria is recognized as a significant cause of mortality and morbidity, with an incidence rate ranging from 36.3 to 50.2/100,000 women and increasing (Jedy-Agba et al. 2012) and becoming a public health threat (Amin et al. 2017). Other work in this area includes Zainal et al. (2013) and Dahlui et al. (2011), among many other works.

Africa has embarked on a development imperative, and the importance of women's role in this development cannot be overemphasized. The policymaker's attention must be drawn to the potential effect of breast cancer on women's productive lives and the factors that the policymaker might target to reduce these effects. However, this policymaker needs to be informed with empirical evidence, which has been limited in most African countries (Jedy-Agba et al. 2012) and Nigeria in particular. Hence, this paper aims to analyze women's productivity when doing modest work in Nigeria based on primary data. It is expected that the evidence will provide policymakers with information on the extent of damage and the factors they can act upon to deal with the issues or mitigate the issue of $\mathrm{BC}$ among the African population. The paper contributes to the ongoing work in this area by showing evidence for women from marginalized communities in Nigeria. This paper contribution lies in (1) analyzing productivity and (2) analyzing the controlled impact of $\mathrm{BC}$ using the simple linear regression model.

\subsection{Theoretical Literature}

The cost of illness theory (COIT) explains the productivity effects of BC. The theory describes how illness affects labour supply and the costs of treating diseases (Jefferson et al. 2000; Clabaugh and Ward 2008; Changik 2014). The COIT explains the consequences of illnesses in terms of loss of career jobs. These consequences are severe in the private sector (Binuomoyo 2010). Unlike the public sector workers, who have more generous leave policies, private sector workers pay dearly for illness-related work absence. In the case of women, these effects of the workforce's decline reduce their well-being. It also leads to a fall in the aggregate labour force and widening the gap between the male and female workforce. No doubt, this deadly disease reduces the working hours for both the patient and the caregiver, most especially public sector workers. Veenstra et al. (2017) revealed that about $32 \%$ of the breast cancer patient caregivers adjust their working hours downward due to the patients' cancer.

The COIT also distinguishes between a direct cost and indirect cost of the cost of illness. The direct costs include the financial costs of the disease in terms of treatment, while the indirect cost concerns the labour supply loss, hours of work lost, decrease in output per hour for the individual and for members of the family who might be involved in the assistance rendered to the sick member. These indirect costs are usually termed 
opportunity costs in economics (Koopmanschap et al. 1995; Johannesson and Karlsson 1997; Goeree et al. 1999; Kirschstein 2000).

The analysis of the cost of illness follows many approaches in measuring the indirect costs. These approaches consist of human capital methods, friction costs methods (FCM), and the willingness-to-pay method. Human capital methods explain productivity losses in relation to the value of human capital. Since human capital is more productive with education, the approach assigns more value to productivity losses when the sick person is more educated (Changik 2014). The productivity losses associated with morbidity and mortality would be the 'market value' of that individual's future contribution to production in society if she continued to work in full health. The method has been criticized due to a controversial and robust assumption that a worker cannot be replaced even if the unemployment rate is significantly high (Johansson 1995; Mincer 1958; Pauly 1995). Critics of the human capital argue that estimates resulting from the approach are subject to biases in earning patterns. Females, young people, and socioeconomically disadvantaged groups typically earn less. Therefore, their loss in productivity is typically valued lower with this approach. In addition, the human capital approach measures 'potential' lost in productivity, rather than the actual loss incurred by society. This leads to large, estimated values of loss in productivity, particularly for young people's chronic conditions. This criticism led to the friction cost method (FCM) theory, which estimates the time illness takes away from work. The FCM proposes that society only incurs losses during the period it takes to replace a worker (the so-called 'friction period') with internal labor reserves taking up a missing employee's slack in the short term. For longer-term or permanent workplace departures, the FCM takes care of replacement cost. Hence, the friction cost (initial disruption costs plus training costs) is limited to the illness, injury or premature death of the short-term period defined as the 'friction period.' It is presumed that the FCM will estimate a lower cost than the human capital since the friction period is shorter than the long-run period contemplated in the human capital method. Since the FCM assumes that impairment or premature death will not affect the total productivity following the friction period, it is highly controversial and even paradoxical to conclude that illness, injuries, and premature deaths would significantly reduce the total productivity. The willingness to pay method that value illness costs in terms of the patient's willingness to pay to get rid of that illness. Despite the criticism against human capital methods, it is more conducive to the empirical investigation of illness's cost and remains the most widely applied method. The FCM and human capital theory guide the analysis in this paper. The next section discusses empirical work on the productivity and financial effects of BC.

\subsection{Review of Empirical Studies on the Productivity Effect of Breast Cancer: International Experience}

Various theories highlighted in Section 2 above have been tested through some identified scholars' empirical works in literature. This literature is reviewed below.

Francisci et al. (2020) estimated total direct health care costs associated with the diagnosis and treatment of women with BC in Italy. Their study also examined the distribution by service type according to the disease pathway and patient characteristics. Data on patients provided by population-based Cancer Registries were linked at individual levels with data on healthcare services and corresponding claims from administrative databases. Results indicated that out of 49,272 participants, $15.2 \%$ were in the initial phase absorbing $42 \%$ of the healthcare services, $79.7 \%$ in the continuing phase absorbing $44 \%$ of the healthcare services, and $5.1 \%$ in the final phase absorbing $14 \%$ of the healthcare services. Hospitalization was the most critical cost driver, accounting for over $55 \%$ of the total costs. The evidence produced by the study can be used to better plan the healthcare services allocation.

Lauzier et al. (2008) argued that wage losses after BC may result in a considerable financial burden. The study assessed wage losses, their determinants, and the associations between wage losses and changes for the worse in the family's financial situation among Canadian women over the first 12 months after diagnosing early breast cancer 
on 962 patients with BC. A cohort study among women with breast cancer from eight hospitals throughout the province of Quebec was conducted. Information that permitted the calculation of wage losses and information on potential determinants of wage losses were collected by three pretested telephone interviews conducted over the year following the start of treatment. Findings revealed a proportion of annual wages lost due to breast cancer. Multivariable analysis of variance using the general linear model was used to identify personal, medical, and employment characteristics associated with the proportion of wages lost. On average, these workers lost $27 \%$ of their projected usual annual wages (median $=19 \%$ ) after compensation had been considered. Multivariable analysis showed that a higher percentage of lost wages was statistically significantly associated with a lower level of wage losses and their effects on the financial situation constitute an essential adverse consequence of breast cancer in Canada.

Mahmood et al. (2018) conducted a study to explore the cost (i.e., direct medical costs, direct non-medical costs, and indirect nonmedical costs) incurred by breast cancer patients and their families over diagnosis and treatment. Methods of analysis included data collection from 200 BC patients at two hospitals in Lahore, Punjab, Pakistan, by employing a purposive sampling technique. Costs were aggregated into three categories and compared with each other. Results showed that direct medical care (USD 1262.18/local currency (PKR) 129,717) is the most considerable expense, followed by direct non-medical (USD 310.88/PKR 31,950) and indirect non-medical costs (USD 273.38/PKR 28,096). The results of this study provide rich insight into the financial burden borne by households of breast cancer patients and suggest policy implications.

Gordon et al. (2007) examined and sought to identify the direct and indirect economic losses to breast cancer survivors in Australia. A longitudinal, population-based study of 287 women was used to explore economic outcomes (costs and loss of income) for women with breast cancer 0-18 months post-diagnosis. Survey methods were adopted to collect data on out-of-pocket costs, caregiving support, paid and unpaid work reductions, and participants' perceptions of these financial impacts. Bootstrapping was used to estimate $95 \%$ confidence intervals around means. Data were sub-grouped by cost type, age category, and disease severity. Lost income, health service expenditures, and lost unpaid work were the most significant economic burden sources. Women with positive lymph nodes reported significantly higher costs than those with malicious lymph nodes (USD 6674 versus USD 3533, $p<0.001$ ), and younger women ( $<$ or $=50$ years) with positive lymph nodes experienced costs 80\% greater than older women (USD 8880 versus USD 4937, $p<0.001)$. Economic costs related to breast cancer may continue to affect women 18 months post-diagnosis. The outcome of the economic research adds an essential dimension for understanding the impact of BC.

Capri and Russo (2017) investigated breast cancer cost during the phases of the diagnostic, therapeutic sequence in Italy between 2007 and 2011. To identify breast cancer cases diagnosed between 2007 and 2011, the study extracted data from the cancer registry from the Health Protection Agency in the Province of Milan. A generalized linear model alongside the Charlson comorbidity index was adopted to control for patient age, cancer stage, and mean costs for each hospital used for the study. Regression analyses were based on dependent variables of individual charges against the independent variables: Age at hospital volume, diagnosis, stage, educational level, job category, comorbidities, marital status, and deprivation index. On average, for each subject, the costs were collected over 2.5 years. The study reported that patients' age, stage of the tumor, and employment level significantly impact on individual costs. According to the Canadian Breast Cancer Network Survey Report (2010), about $16 \%$ of the BC patients surveyed had their jobs terminated while $12 \%$ could not return to their previous employment with the same title and salary. Similarly, the University of Michigan Report (2014) revealed that about 27\% of job loss were recorded among the $\mathrm{BC}$ patients who underwent chemotherapy. 


\subsection{Review of Empirical Studies on the Productivity Effect of Breast Cancer: Nigeria Experience}

Mustapha (2015) observed that the economic burden of cancer affects not only cancer patients and their families but also society. In Nigeria, there is a dearth of information about the economic burden of cancer on patients. However, an estimation of the cost burden of cancers needs to be done to show how much spending is allocated to the problem. The study aimed at estimating the economic burden of cancer on patients treated at the Radiotherapy department of University College Hospital, Ibadan, and compare the findings with previous studies. The study was a cross-sectional study based on a probabilistic simple random sampling of patients with cancer $(n=220)$. Patients were interviewed using a set of questionnaires which addresses socio-demographic and economic questions involving medical and non-medical costs (direct medical costs) and productivity losses (indirect costs). Data obtained were analyzed using the statistical package for social sciences (SPSS) Version 21.0. (SPSS Inc. Chicago, IL, USA). Descriptive statistics such as frequencies (\%), mean, standard deviation, median, range, and $p$-value were used to highlight the data's essential and relevant features. For ease of analysis, some variables, such as socio-demographic, direct, and indirect costs, were grouped or categorized.

Ahmad et al. (2015) aimed to determine the costs and burden associated with cancer chemotherapy by calculating the direct costs with or without co-morbidities in patients attending Ahmadu Bello University Teaching Hospital (ABUTH) Zaria, Nigeria. This was a retrospective observational study conducted on cancer patients' data and cost details using structured questionnaire interviews. These data were reviewed and analyzed for relevant inferences. Healthcare-associated costs were calculated based on the patients' total amount to that of the total number of patients. A total of 31 patients were enrolled, out of which 26 supplied complete healthcare-related cost details required for the study. The average cost for cancer chemotherapy was 29,034.4 (Nigerian Naira). The price was least among those within the age group 26-35 years, 20,405 (Nigerian Naira), and highest among 51-70 years, 62,550 (Nigerian Naira). In addition, 19 (69.3\%) of patients complained of loss of productivity for over $>7$ days/month, while $4(13.4 \%)$ never had any decline in their productivity. Moreover, $13(50 \%)$ of the patients strongly agreed with difficulty in financing cancer chemotherapy, while all strongly support the need for inclusion of chemotherapeutic agents in the national health insurance scheme and the need for government and non-government interventions through cost relieve programs. The average price of cancer chemotherapy at ABUTH Zaria was 29,034.4 (Nigerian Naira). Considering the per capita income of an average Nigerian, cancer chemotherapy places a high financial burden on these patients. This justifies the need for governmental and non-governmental interventional programs towards relieving these patients.

This study has reviewed various empirical works of scholars on BC both in Nigeria and beyond. Most studies focused on the $\mathrm{BC}$ determinants, such as demographic and socioeconomic factors. The evidence on the BC labour market and income effects in contexts where women's economic activities are marginal has been limited. This paper contributed to the literature by providing evidence for the women in Southwest Nigeria.

\section{Methodology}

\subsection{Location of the Study}

The research took place at six Southwest Nigerian hospitals and was based on primary data gathering. The area's choice was motivated by the existence of hospitals that attract most cancer patients. These hospitals have consultants and chemotherapy equipment supplied by the government than any other hospital in the country. The areas have the Federal Teaching Hospitals Ido Ekiti, Ekiti State University teaching hospital, Ekiti State Hospital. The study interviewed 100, 70, and 30 women at these hospitals, respectively. 


\subsection{Population}

The target population consists of in- and outpatient women with BC aged 21-65 years. The age bracket is purposely selected to deal with the population of economically active women.

\subsubsection{Sample Size}

Knowing that the margin of error for confidence intervals is affected by the sample size, the study first used the conventional margin of $5 \%$ error. Then, it determined the minimum sample size that allows being within that error. Our sampling strategy was then to be guided by that estimate of the minimum sample size. To determine the minimum sample size to work with, the study used the following formula:

$$
n \geq \frac{z^{2} * \sigma *(1-\sigma)}{(M O E)^{2}}
$$

where $n$ is the minimum required sample size, $z$ is the $z$-score needed to get the margin of error (1.96 in this study), MOE is the margin of error (0.05 in this study), and $\sigma$ is the population of breast cancer women standard deviation. The standard deviation of women with breast cancer was unknown and was estimated at 0.12 based on the pilot study. Applying our parameters in the Formula (1), we got the minimum sample size of:

$$
n \geq \frac{1.96^{2} * 0.12 *(1-0.12)}{(0.05)^{2}}
$$

The study worked with a sample size of 200 women with breast cancer, considering that some would drop out. Questionnaires were distributed to these women by the principal investigator and his assistants.

\subsubsection{Data Collection}

The questionnaire was distributed among 200 women. The data collected ranged from categorical data to continuous data. Categorical data consisted of data collected using questions that sought the perception of women. Continuous data consisted of data collected in terms of the number of hours worked and income earned. This study is part of a project with multiple research questions. The researchers conducted, fleiss multi-rater Kappa test, reliability test using Cronbach's alpha test and case processing summary to validate the authenticity of the result (see Tables A3-A5 in the Appendix A for details). Therefore, the data used in this paper was part of the broader dataset that was gathered throughout 6 months from October 2019 to March 2020. Since each study participant was contacted once with no further follow-up in this period, the collected data were cross-sectional. We distributed the questionnaires to women participants until we reached the required sample size in 6 months.

\subsubsection{Ethical Matters}

To access the in- and outpatients with $\mathrm{BC}$, the researcher received official permission from the Biometric research ethics committee (BREC) unit at the University of Kwazulu Natal South Africa with protocol permit number BREC/000009042019. This permission was received after the principal researcher received a training certificate from the Clinical Trial Centre, the University of Hong Kong, on 14 December 2019.

\section{Data Analysis}

The study used both descriptive analysis and inferential techniques. In the descriptive analysis, we compare income and productivity before and after the incidence of $\mathrm{BC}$. In the inferential analysis, the BC independent effect is analyzed alongside other factors affecting these variables. 


\subsection{Measurement of Variables}

Breast cancer: Incidence of breast cancer was the variable of interest to this study and was measured based on clinically confirmed cases according to which the breast cells grow out of control.

Productivity: Productivity was measured in terms of workhours lost in a specific working period (day or week) as per Matebu and Shibabaw (2015).

Income: Income was measured in terms of naira earned per month (1 USD = 381 Naira as per September). Women reported their incomes in Naira on the questionnaire that were distributed to them. In the results, we report the USD equivalent of these incomes.

\subsection{The Analysis}

The productivity effect of $\mathrm{BC}$ among women was distinguished across employment since jobs are associated with productivity loss. This study distinguished five categories of the women's labour force, namely: Public servants (PS); self-employed women (SE); full housewife (FHW); private company servants (PCS), and students (S). Women were asked to report the time used when they were active and healthy at the workplace and time used in labour when $\mathrm{BC}$ has been clinically confirmed. The effect of $\mathrm{BC}$ on income and productivity was observed by comparing the difference between work hours pre-BC and post-BC. The study also sought to ask the participants their perception about issues that might affect their income and productivity, such as complaints arising at the workplace for a frequent visitor to the hospital and health condition. This part of the analysis was done using descriptive statistics. Details of questionnaire design affecting the income and productivity of participants could be found in the appendices section (see Tables A1 and A2.)

Since BC might not be the only factor influencing productivity, the study sought to analyze its controlled effect by including other key variables that are likely to affect productivity, such as education and occupational status. Further understanding of productivity loss entailed asking women their perception regarding workplace productivity using a Likert scale questionnaire.

\subsection{Descriptive Statistics}

The first part of the results reports descriptive statistics about breast cancer's income and productivity among women in Nigeria. Table 1 starts with the undemanding of the distribution of income among these women.

Table 1. Description of income distribution among women with breast cancer in Nigeria before and after the incidence of BC.

\begin{tabular}{cccc}
\hline $\begin{array}{c}\text { Income Brackets } \\
\text { the USD = 381 Naira as at } \\
\text { September 2020 }\end{array}$ & Number of Women & $\begin{array}{c}\text { Average Earning before } \\
\text { Confirmation of Breast } \\
\text { Cancer per Months }\end{array}$ & $\begin{array}{c}\text { Average Earning after } \\
\text { Confirmation of Breast Cancer }\end{array}$ \\
\hline$<15,000$ Naira & 45 & 100,000 (USD 26) & 7000 (USD 23) \\
20,000-50,000 Naira & 121 & 40,000 (USD 101) & 35,000 (USD 23) \\
$50,000-80,000$ Naira & 24 & 60,000 (USD 157) & 50,000 (USD 23) \\
$>80,000$ Naira & 7 & 85,000 (USD 223) & 68,000 (USD 23) \\
\hline
\end{tabular}

Source: Authors' computation, 2021.

As shown in Table 1, women were grouped into categorical average income groups, distinguishing two scenarios: Before BC and after BC. It is worth noting that incomes decrease after the occurrence of $\mathrm{BC}$ in all income groups. Figures 1-3 give the distribution of the details of income in each income group. We also noted that women in the lowest income categories are the most affected by BC. 


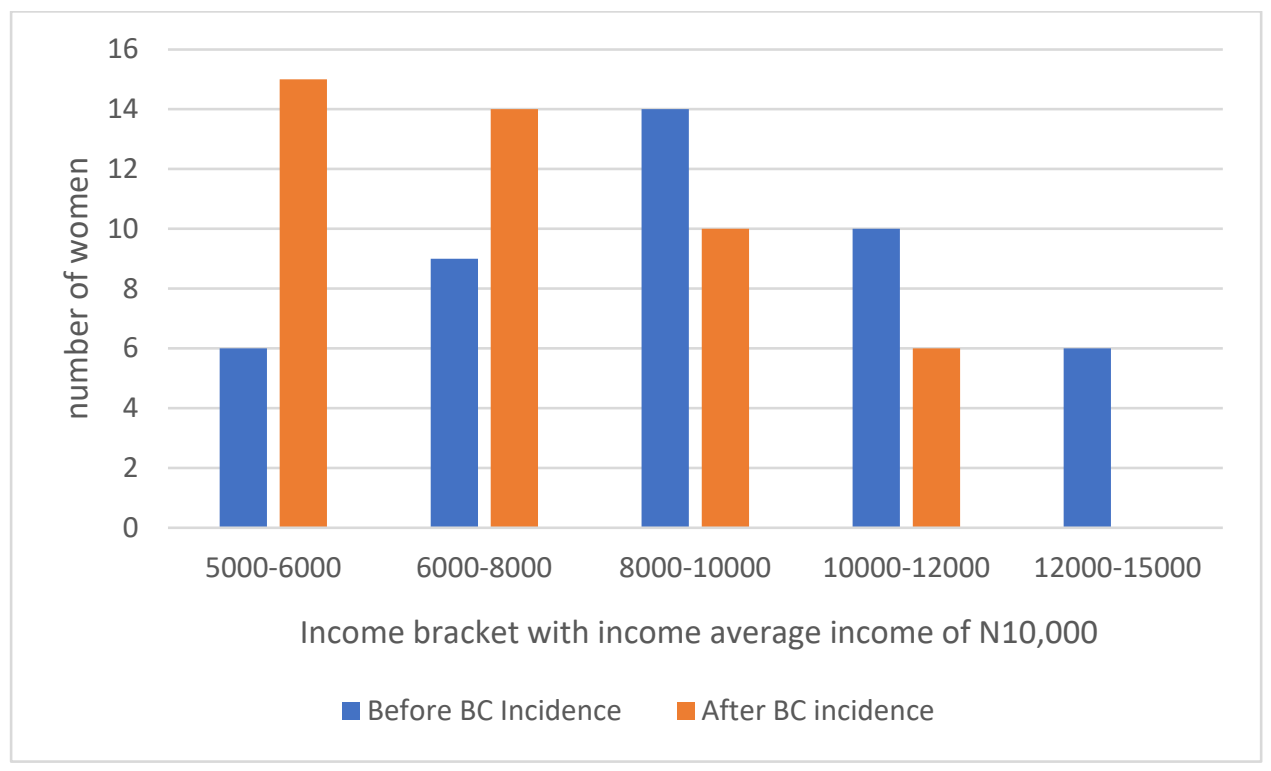

Figure 1. Showing contrasted low-income bracket before and after the incidence of BC. Source: Authors' computation, 2021.

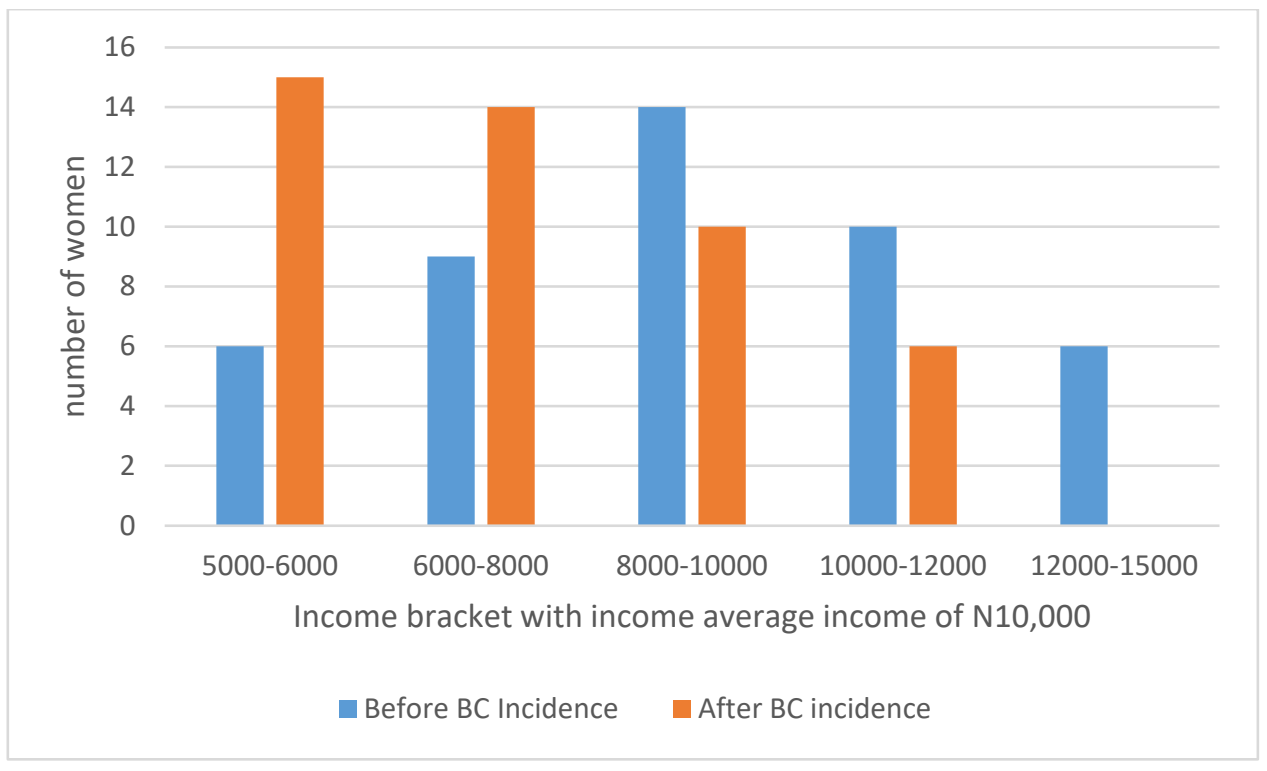

Figure 2. Showing contrasted middle-income bracket before and after the incidence of BC. Source: Authors' computation, 2021.

Figures 1-3 depict average monthly income groups of $\$ 10,000$, $\$ 40,000, \$ 60,000$ among women with confirmed BC cases in Southwest Nigeria. As Figures 1-3 show, BC cancer tends to move women in the lower-income brackets. The Figure shows that we have six women in the income bracket 12,000-15,000 Naira before BC. After BC, there is no single woman in this bracket. Rather, we have women shifting in lower-income brackets. These results paint similar pictures on other income-brackets with an average income of $\$ 40,000$ and 60,000 , respectively.

As Figure 4 shows, before breast cancer (BBC), most women worked between 20 and 25 days a month, with more women working 23 days a month. Before breast cancer, the average number of days a woman worked was 23 days. After breast cancer (ABC), the average number of days worked in this scenario are less than 20 days. This result suggests that, on average, women lose an average number of more than 3 days a month due to $\mathrm{BC}$. 
Productivity loss in this group of women is further investigated among women who had $\mathrm{BC}$ cases confirmed.

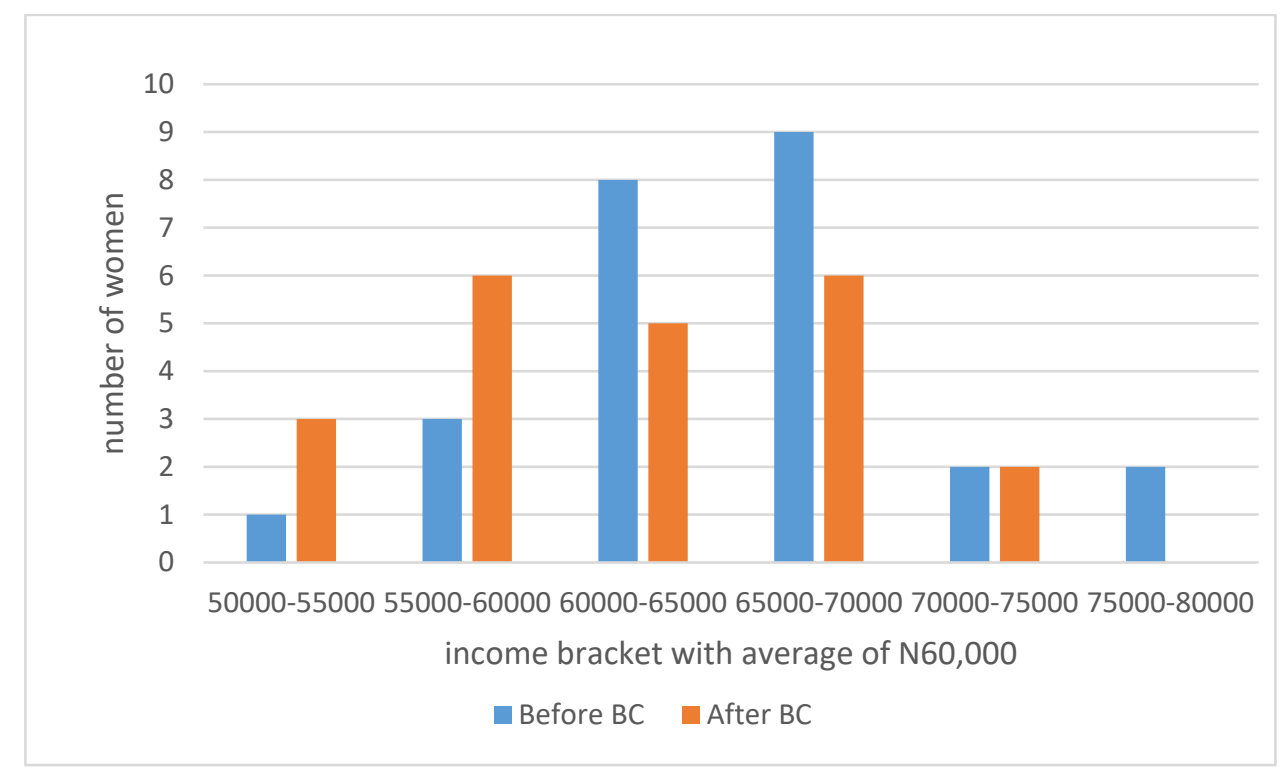

Figure 3. Showing contrasted upper-income bracket before and after the incidence of BC. Source: Authors' computation, 2021.

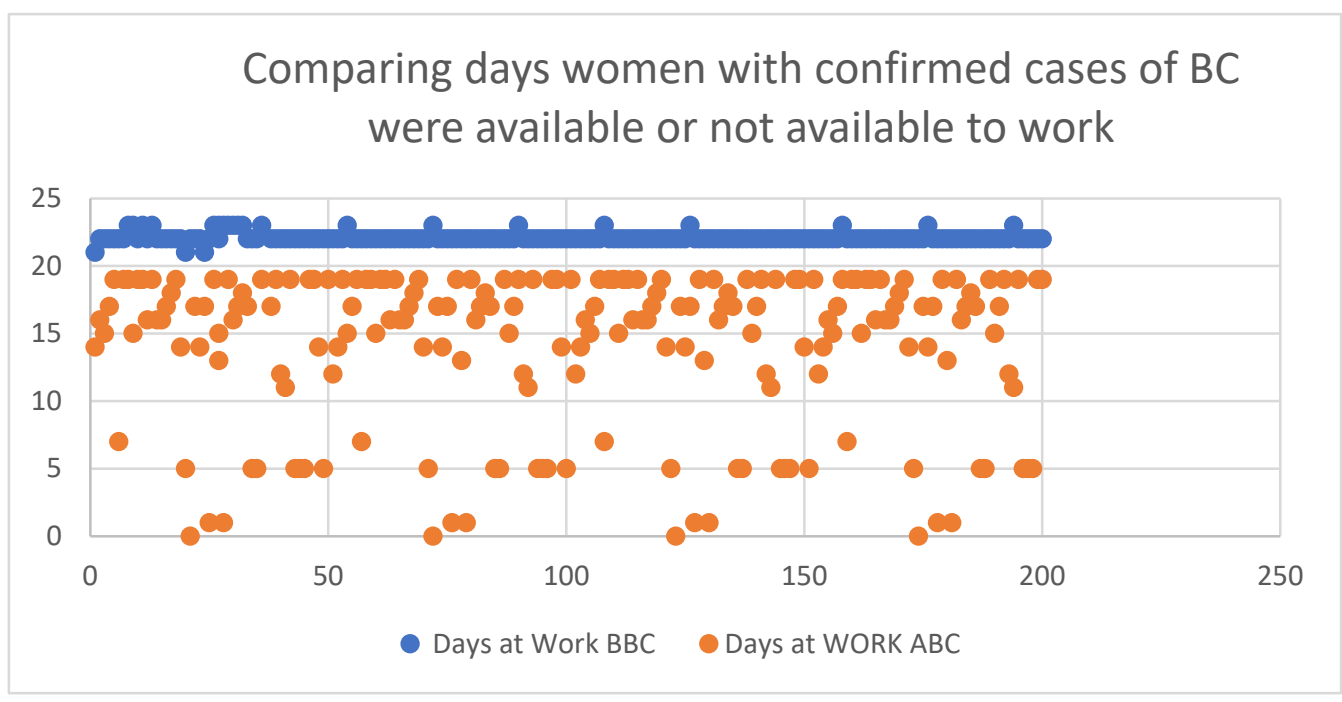

Figure 4. Compares the distribution of the number of days (in a month) available for work before BC and after BC. Source: Authors' computation, 2021.

Table 2 showcases the descriptive statistics on productivity loss. As seen in the table, the study deducted the total number of days absent from work from the 22 working days to arrive at the productivity decline. The result indicates that $62 \%$ (124 women) of the 200 observed women were absent at the workplace for 7 days on average each in a month. The missing 7 days indicate a $31.8 \%$ productivity loss at the workplace in that month. The other row in the table can be interpreted in the same manner. The Table shows that each woman loses at least $\$ 320$ every month in terms of income due to breast cancer. This finding supports the argument of friction cost, indirect cost, and cost of illness theory, where human capital concepts explain productivity losses due to illness. The results also show that conditions can affect patients' well-being in terms of loss of incomes, depending on the wage rate (Changik 2014). 
Table 2. Descriptive statistics on productivity loss.

\begin{tabular}{ccccc}
\hline $\begin{array}{c}\text { Total Breast } \\
\text { Cancer Patients }\end{array}$ & $\begin{array}{c}\text { Average Days BC } \\
\text { Patients Were Absent } \\
\text { from Work (Monthly) }\end{array}$ & $\begin{array}{c}\text { Loss of Productivity } \\
\text { Concerning Days } \\
\text { Absent from Work }\end{array}$ & $\begin{array}{c}\text { \% Losses in } \\
\text { Productivity }\end{array}$ & $\begin{array}{c}\text { The Monetary Value of } \\
\text { the Days Lost Per Woman }\end{array}$ \\
\hline $32(16 \%)$ & 10 & $32 * 10$ days (320) & $45.5 \%$ & 320 \\
\hline $124(62 \%)$ & 7 & $124 * 7$ days (868) & $31.8 \%$ & 868 \\
\hline $44(22 \%)$ & 14 & $44^{*} 14$ days $(616)$ & $68.2 \%$ & 616 \\
\hline
\end{tabular}

Source: Authors' computations, losses in productivity $=$ number of days absent $/ 22^{*} 100$. The average percentage of this calculation is reported in column 4 .

The study also reported more specifically on the loss of income. Again, to aid the conduct of the analysis of cancer effects on different income groups, the classification results are found in Table 3 below. This section classified women's income distribution with breast cancer in Southwest Nigeria into four categories: (1) Lower income group: This group barely survived livelihood with $¥ 10,000$. (2) Middle-income group: This income group is made up of $\$ 40,000$ monthly income capacity and barely breaks even from the poverty line of USD 2 per day, as specified by the World Health Organization (WHO). (3) The third category is the upper-middle-income group and earns a monthly $\$ 60,000$. Livelihood within this income group of women is average in Nigeria. (4) Lastly, we have the high-income group category, which is financially stable in Nigeria as they earn above $\$ 60,000$. It is worth noting again that 1 USD $=387$ Naira at the time of the investigation.

Table 3. Measuring income variations before and after BC incidence as an indication of economic impact.

\begin{tabular}{|c|c|c|c|c|}
\hline Income Distribution & Category A & Category B & Category C & Category D \\
\hline $\begin{array}{l}\text { Average income before the } \\
\text { incidence of breast cancer }\end{array}$ & $\mathrm{N} 10,000$ & $\$ 40,000$ & $\mathrm{~N} 60,000$ & $\$ 85,000$ \\
\hline Ratio of category to total jobs & $(22.5 \%)$ & $(62 \%)$ & $(12 \%)$ & $(3.5 \%)$ \\
\hline \multicolumn{5}{|c|}{ Changes in Income after breast cancer according to income distribution } \\
\hline Economic Impact & Increase income & $\begin{array}{l}\text { Decrease in income in } \\
\text { other members }\end{array}$ & No change in income & \\
\hline Category A $(\mathrm{N10,000)} 45$ women & $38 \%$ (17 members) & $62 \%$ (28 members) & $0 \%$ (no member) & \\
\hline Category B $(\mathrm{N} 40,000) 124$ women & $13.7 \%$ & $70.2 \%$ & $14.3 \%$ & \\
\hline Category C ( $(60,000) 24$ women & $16.7 \%$ & $83.3 \%$ & $0 \%$ & \\
\hline Category D > 85,000 (7 women) & $100 \%$ & $0 \%$ & $0 \%$ & \\
\hline
\end{tabular}

Table 3 shows the percentage of women who see their income change due to BC. It clearly shows that more than half $(62 \%)$ of women in $\$ 10,000$ income categories see their income decrease. A more significant percentage of women in the income categories see their income decrease even more in the average income category of $\$ 40,000$, with $70 \%$ of the women having a decrease in income. The corresponding percentage for the average income category of $\$ 60,000$ is $83 \%$. The results also suggest a declining percentage of women seeing their income increase after the occurrence of BC. Some donations from benefactors justify the higher increase in income among women in lower-income classes. An unexpected result is that some percentage of women in income groups $\$ 40,000,60,000$ and 85,000 see their income increase regardless of cancer. These could consist of some exceptional cases of participants with peculiar features. See Table A2 in Appendix A for more details

In addition to the observed productivity loss, the study assessed women's perception of the role of breast cancer in productivity. The results are summarized in Table 4 . 
Table 4. Self-assessed productivity at the workplace by women with breast cancer in Southwest Nigeria.

\begin{tabular}{|c|c|c|c|c|c|}
\hline \multicolumn{6}{|c|}{ Productivity at the Workplace } \\
\hline & SA & A & NTR & DA & SD \\
\hline \multicolumn{6}{|l|}{ PUBLIC SERVANTS = 28 (14\%) } \\
\hline $\begin{array}{l}\text { Complaint arising at the workplace for } \\
\text { frequent visits to the hospital }\end{array}$ & $25.23 \%$ & $25.23 \%$ & $11.11 \%$ & $11.11 \%$ & $25.93 \%$ \\
\hline $\begin{array}{l}\text { Health condition of BC limiting productivity } \\
\text { at the workplace }\end{array}$ & $44.44 \%$ & $29.63 \%$ & $11.11 \%$ & $0 \%$ & $14.81 \%$ \\
\hline $\begin{array}{l}\text { Increase of idle machine due to low } \\
\text { productivity at the workplace }\end{array}$ & $48.15 \%$ & $14.82 \%$ & $0 \%$ & $11.11 \%$ & $25.93 \%$ \\
\hline $\begin{array}{l}\text { Extra financial sources now cushion losses } \\
\text { and decline productivity }\end{array}$ & $51.85 \%$ & $14.81 \%$ & $11.11 \%$ & $0 \%$ & $22.22 \%$ \\
\hline $\begin{array}{l}\text { Significant cost increase at the workplace due } \\
\text { to illness }\end{array}$ & $22.22 \%$ & $11.11 \%$ & $40.74 \%$ & $0 \%$ & $25.93 \%$ \\
\hline $\begin{array}{l}\text { I agree to the rising, hiring, and training costs } \\
\text { at the workplace since } \mathrm{BC}\end{array}$ & $25.93 \%$ & $11.11 \%$ & $37.04 \%$ & $0 \%$ & $25.93 \%$ \\
\hline \multicolumn{6}{|l|}{ SELF EMPLOYED = $123(61.5 \%)$} \\
\hline $\begin{array}{l}\text { Complaint arising at the workplace for } \\
\text { frequent visits to the hospital }\end{array}$ & $45.53 \%$ & $5.69 \%$ & $27.64 \%$ & $8.13 \%$ & $13.01 \%$ \\
\hline $\begin{array}{l}\text { Health condition of BC limiting productivity } \\
\text { at the workplace }\end{array}$ & $63.41 \%$ & $13.01 \%$ & $12.20 \%$ & $5.69 \%$ & $4.88 \%$ \\
\hline $\begin{array}{l}\text { Increase of idle machine due to low } \\
\text { productivity at the workplace }\end{array}$ & $39.02 \%$ & $17.07 \%$ & $21.14 \%$ & $17.87 \%$ & $4.88 \%$ \\
\hline $\begin{array}{l}\text { Extra financial sources now cushion losses } \\
\text { and decline productivity }\end{array}$ & $45.53 \%$ & $21.95 \%$ & $11.38 \%$ & $16.26 \%$ & $4.88 \%$ \\
\hline $\begin{array}{l}\text { Significant cost increase at the workplace due } \\
\text { to illness }\end{array}$ & $39.84 \%$ & $19.51 \%$ & $29.27 \%$ & $10.57 \%$ & $0.91 \%$ \\
\hline $\begin{array}{l}\text { I agree to the rising, hiring, and training costs } \\
\text { at the workplace since BC }\end{array}$ & $34.15 \%$ & $12.20 \%$ & $38.21 \%$ & $4.88 \%$ & $10.57 \%$ \\
\hline \multicolumn{6}{|l|}{$\mathrm{STD}=35.651 ; \mathrm{MEAN}=62.00$} \\
\hline \multicolumn{6}{|l|}{ FULL HOUSEWIFE = $23(11.5 \%)$} \\
\hline $\begin{array}{l}\text { Complaint arising at the workplace for } \\
\text { frequent visits to the hospital }\end{array}$ & $17.40 \%$ & $17.40 \%$ & $65.22 \%$ & $0 \%$ & $0 \%$ \\
\hline $\begin{array}{l}\text { Health condition of BC limiting productivity } \\
\text { at the workplace }\end{array}$ & $30.43 \%$ & $0 \%$ & $52.17 \%$ & $0 \%$ & $17.40 \%$ \\
\hline $\begin{array}{l}\text { Increase of idle machine due to low } \\
\text { productivity at the workplace }\end{array}$ & $17.40 \%$ & $0 \%$ & $82.61 \%$ & $0 \%$ & $0 \%$ \\
\hline $\begin{array}{l}\text { Extra financial sources now cushion losses } \\
\text { and decline productivity }\end{array}$ & $34.78 \%$ & $17.39 \%$ & $30.43 \%$ & $0 \%$ & $17.39 \%$ \\
\hline $\begin{array}{l}\text { Significant cost increase at the workplace due } \\
\text { to illness }\end{array}$ & $17.39 \%$ & $0 \%$ & $68.57 \%$ & $13.04 \%$ & $0 \%$ \\
\hline $\begin{array}{l}\text { I agree to the rising, hiring, and training costs } \\
\text { at the workplace since } B C\end{array}$ & $0 \%$ & $0 \%$ & $100 \%$ & $0 \%$ & $0 \%$ \\
\hline \multicolumn{6}{|l|}{$\begin{array}{l}\text { PRIVATE COMPANY SERVANTS = } 22 \\
(\mathbf{1 1} \%)\end{array}$} \\
\hline $\begin{array}{l}\text { Complaint arising at the workplace for } \\
\text { frequent visits to the hospital }\end{array}$ & $63.64 \%$ & $18.18 \%$ & $18.18 \%$ & $0 \%$ & $0 \%$ \\
\hline $\begin{array}{l}\text { Health condition of } \mathrm{BC} \text { limiting productivity } \\
\text { at the workplace }\end{array}$ & $100 \%$ & $0 \%$ & $0 \%$ & $0 \%$ & $0 \%$ \\
\hline
\end{tabular}


Table 4. Cont.

\begin{tabular}{|c|c|c|c|c|c|}
\hline \multicolumn{6}{|c|}{ Productivity at the Workplace } \\
\hline & SA & $\mathbf{A}$ & NTR & DA & SD \\
\hline $\begin{array}{l}\text { Increase of idle machine due to low } \\
\text { productivity at the workplace }\end{array}$ & $50 \%$ & $0 \%$ & $50 \%$ & $0 \%$ & $0 \%$ \\
\hline $\begin{array}{l}\text { Extra financial sources now cushion losses } \\
\text { and decline productivity }\end{array}$ & $68.18 \%$ & $0 \%$ & $0 \%$ & $13.64 \%$ & $18.18 \%$ \\
\hline $\begin{array}{l}\text { Significant cost increase at the workplace due } \\
\text { to illness }\end{array}$ & $18.18 \%$ & $31.82 \%$ & $36.36 \%$ & $13.64 \%$ & $0 \%$ \\
\hline $\begin{array}{l}\text { I agree to the rising, hiring, and training costs } \\
\text { at the workplace since BC }\end{array}$ & $18.18 \%$ & $0 \%$ & $50 \%$ & $31.82 \%$ & $0 \%$ \\
\hline \multicolumn{6}{|l|}{ STUDENTS = $4(2 \%)$} \\
\hline $\begin{array}{l}\text { Complaint arising at the workplace for } \\
\text { frequent visits to the hospital }\end{array}$ & $0 \%$ & $0 \%$ & $100 \%$ & $0 \%$ & $0 \%$ \\
\hline $\begin{array}{l}\text { Health condition of } \mathrm{BC} \text { limiting productivity } \\
\text { at the workplace }\end{array}$ & $0 \%$ & $0 \%$ & $100 \%$ & $0 \%$ & $0 \%$ \\
\hline $\begin{array}{l}\text { Increase of idle machine due to low } \\
\text { productivity at the workplace }\end{array}$ & $0 \%$ & $0 \%$ & $100 \%$ & $0 \%$ & $0 \%$ \\
\hline $\begin{array}{l}\text { Extra financial sources now cushion losses } \\
\text { and decline productivity }\end{array}$ & $0 \%$ & $0 \%$ & $0 \%$ & $100 \%$ & $0 \%$ \\
\hline $\begin{array}{l}\text { Significant cost increase at the workplace due } \\
\text { to illness }\end{array}$ & $0 \%$ & $0 \%$ & $0 \%$ & $0 \%$ & $100 \%$ \\
\hline $\begin{array}{l}\text { I agree to the rising, hiring, and training costs } \\
\text { at the workplace since BC }\end{array}$ & $0 \%$ & $0 \%$ & $0 \%$ & $0 \%$ & $100 \%$ \\
\hline
\end{tabular}

Source: Authors' computation, 2021; Note: SA: Strongly agree; A: Agree; NTR: Neutral; DA: Disagree; SD: Strongly disagree.

Table 4 shows the perception of women with BC in different employment categories of women. The perception differs across women depending on the type of employment. To get clear results, we aggregated the positive categories and the two negative categories of the Likert scale responses by the type of employees.

Whether women suffer complaints of some sort due to limited productivity due to breast cancer, about $50 \%$ of public servants (PS) answered yes (SA and A), and $36 \%$ answered no. Among the self-employed, about 51\% answered yes, and 19\% answered no. Among housewives, 34 answered yes, none of the housewives disagreed. Women working in the private sectors $81.5 \%$ are affected negatively, and $0 \%$ are not. The prevailing opinion in these categories is that it depends on the type of work. Of course, students do not have such a complaint.

Whether the health condition of breast cancer limits productivity at the workplace, $75 \%$ of public servants agreed, $76 \%$ of self-employed agreed, $30 \%$ of homemakers agreed, $100 \%$ of women working in the private sector agree, and no student agreed. According to women's perception, the health condition of cancer is most likely to cause issues, especially in the private sector. Whether BC contributes to the idle machines, $62 \%$ of public servants and $77 \%$ of self-employed agreed, 50 in the private sector answered yes, suggesting a low level of perception, while students are indifferent to this question. This might be that these women are not using machinery in the workplace and students are not productive at this stage.

\section{Simple Linear Regression Analysis}

The section that follows in Tables 5 and 6 test the impact of BC on economic impacts and productivity. This is to ascertain the nexus using simple linear regression analysis on "R Studio". 
Table 5. Impact of BC on income of women with confirmed cases of BC in Nigeria.

\begin{tabular}{cccccc}
\hline & \multirow{2}{*}{ Estimate } & \multirow{2}{*}{ Standard Error } & $p$-Value & \multicolumn{2}{c}{ 95\% Confidence Interval (CI) } \\
\cline { 5 - 6 } & & & & Lower Bound & Upper Bound \\
\hline Intercept & 5.968 & 0.329 & 0.000 & 5.318 & 6.617 \\
\hline BC & -0.195 & 0.052 & 0.000 & 0.092 & 0.298 \\
\hline
\end{tabular}

Source: Authors' computation, 2021.

Table 6. Impact of BC on the productivity of women with confirmed cases of BC in Nigeria.

\begin{tabular}{|c|c|c|c|c|c|}
\hline & \multirow{2}{*}{ Estimate } & \multirow{2}{*}{ Standard Error } & \multirow{2}{*}{$p$-Value } & \multicolumn{2}{|c|}{ 95\% Confidence Interval (CI) } \\
\hline & & & & Lower Bound & Upper Bound \\
\hline Intercept & 5.225 & 0.357 & 0.000 & 4.520 & 5.930 \\
\hline BC & -0.139 & 0.057 & 0.016 & 0.027 & 0.251 \\
\hline
\end{tabular}

Source: Authors' computation, 2021.

Table 5 showcases the result of simple linear regression where $\mathrm{C} 1$ was regressed against $\mathrm{A} 1$ and $\mathrm{A} 2$ using $\mathrm{R}$ studio. Consequently, the impact of $\mathrm{BC}$ on the income of women in Southwest Nigeria with BC were determined. The relationship between the economic impact as a dependent variable and $\mathrm{BC}$ are statistically significant at a $1 \%$ level of significance. From the result, there is a negative relationship between these variables, implying that economic impact decreases with confirmed cases of $\mathrm{BC}$. This result is expected as more confirmed cases of $\mathrm{BC}$ should decrease economic impacts. A close examination of the result from descriptive statistics in Table 4 under low-income group A, B, and C strongly supported this outcome. It simply indicates that the decreasing income only affects low- and middle-income earners. The implication is that higher income earners reap from numerous sources thereby weakening out the effects of BC.

Table 6 revealed the productivity effects of $\mathrm{BC}$ among women in Southwest Nigeria. Productivity was regressed against breast cancer and the intercept, respectively. The result is similar to the result of the effect $\mathrm{BC}$ has on income in Table 5. There is a negative relationship between the confirmed cases of $\mathrm{BC}$ and the productivity of women. This result could be true in developing countries such as Nigeria, where women's job security is low. Hence, women are made to work despite the ailment leading to lower productivity until women cannot work again. At this stage, the replacement of women quickly set in neutralizing the possible productivity losses.

Covariance in this investigation is required to measure the directional relationship between the returns on two questions related to financial with income effect and productivity, productivity and breast cancer, and lastly, financial and income effect and breast cancer. A positive covariance will imply that the related questions jointly move together, while a negative covariance will imply that such pairs of questions move inversely to explain the financial and income effect and productivity as they relate to breast cancer. In theory, covariance measures the nexus between two randomly selected variables. The metric evaluates to what extent and by how much pairs of variables change together. Hence, covariance measures the variance between two explanatory variables under this cancer investigation. The metric does not, however, evaluate the dependency between variables.

From Table 7, only the covariant of financial and income effect and breast cancer questions are jointly significant, as the result indicates. The implication of the well-fitted covariance in this study's problem is that there is a linear measure of "question connectivity". It is positive when the two variables you have at hand are positively connected. Thus, the questions of the model covariance are significant since they measure randomness, strengthening the argument that the relationship is close to zero in random variables. 
Table 7. Showing the covariance of income effect, productivity effects, and breast cancer reality in Southwest Nigeria.

\begin{tabular}{cccccc}
\hline Covariant & Coef. & Std. Err. & $\mathbf{P}>\mathbf{~ z}$ & \multicolumn{2}{c}{ (95\% Conf. Interval) } \\
\hline Income, Product & 0.065896 & 0.297299 & 0.825 & -0.5167996 & 0.6485923 \\
\hline Income, Cancer & 1.30422 & 0.4807562 & 0.007 & 0.361957 & 2.246487 \\
\hline Product, Cancer & 0.16628 & 0.490874 & 0.735 & -0.7958183 & 1.128373 \\
\hline Source: Authors' computation, 2021. & & &
\end{tabular}

\section{Conclusions and Summary for Discussion}

As noted at the beginning of this paper, the study drew evidence from the literature on the declining productivity concerns of the women labour force in Nigeria. Alongside this declining productivity is the growing concern on women's poor health condition, as evidenced by the increasing BC cases among women in Nigeria. The study tested if there is a significant income and the productivity effects of $B C$ among women with clinically confirmed BC in Nigeria. The data were collected using the questionnaires on 200 women having BC in Southwest Nigeria for over 6 months. For the study's method of analysis and estimating technique, the simple linear regression and descriptive analyses were adopted. We provided evidence on the following: (1) $61.5 \%$ of women with BC were self-employed; $62 \%$ of the 200 observed women were absent at the workplace for 7 days each, resulting in total productivity losses in terms of lost days of $31.8 \%$ workdays in this group. Sixteen percent of women in lower-income groups were missing at the workplace for an average of 10 days each, totaling $45.5 \%$ of lost days in this group. Lastly, $22 \%$ of the experimental women were missing at the workplace for more than 2 weeks on average. This indicates $68.2 \%$ productivity loss at the workplace. Evidence from this study further showed that $70.2 \%$ of the total women that are in the middle-income category who received $\mathrm{N} 40,000$ or the equivalent of USD 103 as monthly income witnessed a remarkable decline in monthly payment, while $18.5 \%$ of the women retained the monthly income level despite the clinically confirmed incidence of BC. One hundred and twenty-four (62\%) of the total women under investigation were found in this group. Only 14 women with the incidence of $\mathrm{BC}$ in this income group experienced an increase in income. (2) In analyzing the impact of $\mathrm{BC}$ on patients' income using simple linear regression, the outcome of this relationship is statistically significant, and the coefficient is negative. The results imply that in the case of the non-existence of cancer ailment, women's income is estimated at a certain level. When cancer occurs, that income decreases significantly. A close examination of the result from descriptive statistics in Table 4 under income group A, B, and C strongly supported this outcome. It simply indicates that the impact of $\mathrm{BC}$ is higher in low- and middle-income earners.

The study further investigates the productivity effects of $\mathrm{BC}$ on women with confirmed cases of BC. We got three responses from the various observations collated together as represented by B1 (possibility of productivity decline resulting from absenteeism at the workplace due to BC), B2 (a significant cost increase at the workplace results from the illness of $\mathrm{BC}$ ), and $\mathrm{B} 3$ (the possibility of $\mathrm{BC}$ limiting and restricting productivity at the workplace), respectively. The possibility of productivity to decline resulting from the emergence of $\mathrm{BC}$ ailment is measured in the total average time taken for sick leave over a given period. The result exhibits a negative relationship, indicating that confirmed cases of $\mathrm{BC}$ among women lead to productivity decline resulting from absenteeism at the workplace. In B2, further steps were taken to determine if a significant cost increase at the workplace results from $B C$ illness. The result indicates negative and statistical significance, which is true since fewer confirmed $\mathrm{BC}$ cases among women will increase organizational cost more at the workplace, going by the insurance and health protection policies from trade unions and the government. Cost-effective options such as the layoff of workers will only become socially acceptable and operational with an increasing number of confirmed cases of BC at the workplace. 
However, B3 concerns the possibility of BC limiting and restricting productivity at the workplace. The outcome of our finding indicates statistical significance, but the coefficient is negative. The implication of this result is instructive. An increasing level of BC causes a $13.9 \%$ decrease in productivity level at the workplace. This result supports the outcome of descriptive statistics. (4) The study further compares various income levels of BC patients to know if low income could aggravate the BC increasing risk among women in Nigeria. Averages of observations were randomly selected, and $22.5 \%$ of the respondents received USD 25.839 as monthly income. In addition, 62\% earns USD 103.40 monthly, while 16.5\% earns slightly above USD 155 as monthly income. One hundred and twenty-four of the total women with confirmed cases of breast cancer are middle-income earners, and our investigation confirmed a decline of $70.2 \%$ in revenue and productivity due to the $\mathrm{BC}$ incidence. Evidence from the study showed a high risk of decline in revenue with an increasing incidence of BC. This decline in revenue could be linked with a resultant fall in productivity resulting from absence at the workplace. Low-income levels could account for one reason why $\mathrm{BC}$ could spread as no adequate medical attention was given at the early stages due to financial limitations. From the previous results, it is axiomatic to conclude that our objectives in this study have been achieved. This study makes the following recommendations: (1) Provision should be made for a periodic check of women's breast at no cost at the workplace to lessen BC incidences in Nigeria. It is worth noting again that women's education and counselling on the factors promoting BC should be given the utmost priority in the nation's policy. A policy guaranteeing women's job security in the event of BC should also be established.

Author Contributions: W.G.A. Originality of Ideas; Involves in data gathering, analysis and Interpretation, writing of literatures; J.M. Proof-Reading, and editing, of the whole manuscript, Correction of tables and figures. All authors have read and agreed to the published version of the manuscript.

Funding: University of Kwazulu Natal, College of Law and Management, Durban, South Africa.

Institutional Review Board Statement: To access the in- and outpatients with BC, the researcher received official permission from the Biometric research ethics committee (BREC) unit at the University of Kwazulu Natal South Africa with protocol permit number BREC/000009042019. This permission was received after the principal researcher received a training certificate from the Clinical Trial Centre, the University of Hong Kong, on 14 December 2019.

Informed Consent Statement: The research Unit of the University (BREC) gave permission for the conduct of this study. Again, consent was received from the relevant hospitals. Such documents are available on request.

Data Availability Statement: The dataset will be stored with the College of Law and Management Library, University of KwaZulu Natal in hard drive for five year and it is available on request.

Conflicts of Interest: There is no conflict of interest in this study.

Appendix A

Table A1. Questions/instruments used to measure productivity, finances, and income effects on BC (format).

\begin{tabular}{|c|c|c|c|c|c|c|}
\hline Nos & QUESTIONNAIRE on Income Measurement & SA & A & Nut & DA & SD \\
\hline A1 & Average monthly income of cancer patients before the incidence of $\mathrm{BC}$ & $X$ & & & & \\
\hline A2 & Average monthly income of cancer patients after the incidence of $\mathrm{BC}$ & & $x$ & & & \\
\hline A3 & There is a significant increase on expenses resulting from the incidence of BC & & & $\mathrm{x}$ & & \\
\hline Nos & QUESTIONNAIRE on Productivity Measurement & & & & $x$ & \\
\hline B1 & $\begin{array}{l}\text { There is a possibility of productivity decline resulting from absentiesm at the } \\
\text { workplace due to BC }\end{array}$ & & & & & $\mathrm{X}$ \\
\hline B2 & A significant cost increase at the workplace results from illness of BC & & & & $X$ & \\
\hline
\end{tabular}


Table A1. Cont.

\begin{tabular}{|c|c|c|c|c|c|c|}
\hline Nos & QUESTIONNAIRE on Income Measurement & SA & A & Nut & DA & SD \\
\hline B3 & The possibility of BC limiting and restricting productivity at the workplace. & & & $X$ & & \\
\hline Nos & QUESTIONNAIRE on the confirmed incidence of BC & & $X$ & & & \\
\hline $\mathrm{C} 1$ & Agreement that the patient has $\mathrm{BC}$ without the help of a consultant & $\mathrm{X}$ & & & & \\
\hline enixC2 & Agreement to know the early sign of $\mathrm{BC}$ & & $X$ & & & \\
\hline $\mathrm{C} 3$ & Agreement that a test through a medical doctor clinically confirms the case of $\mathrm{BC}$ & & & $x$ & & \\
\hline
\end{tabular}

Table A2. QUESTIONNAIRE instrument on Income Measurement.

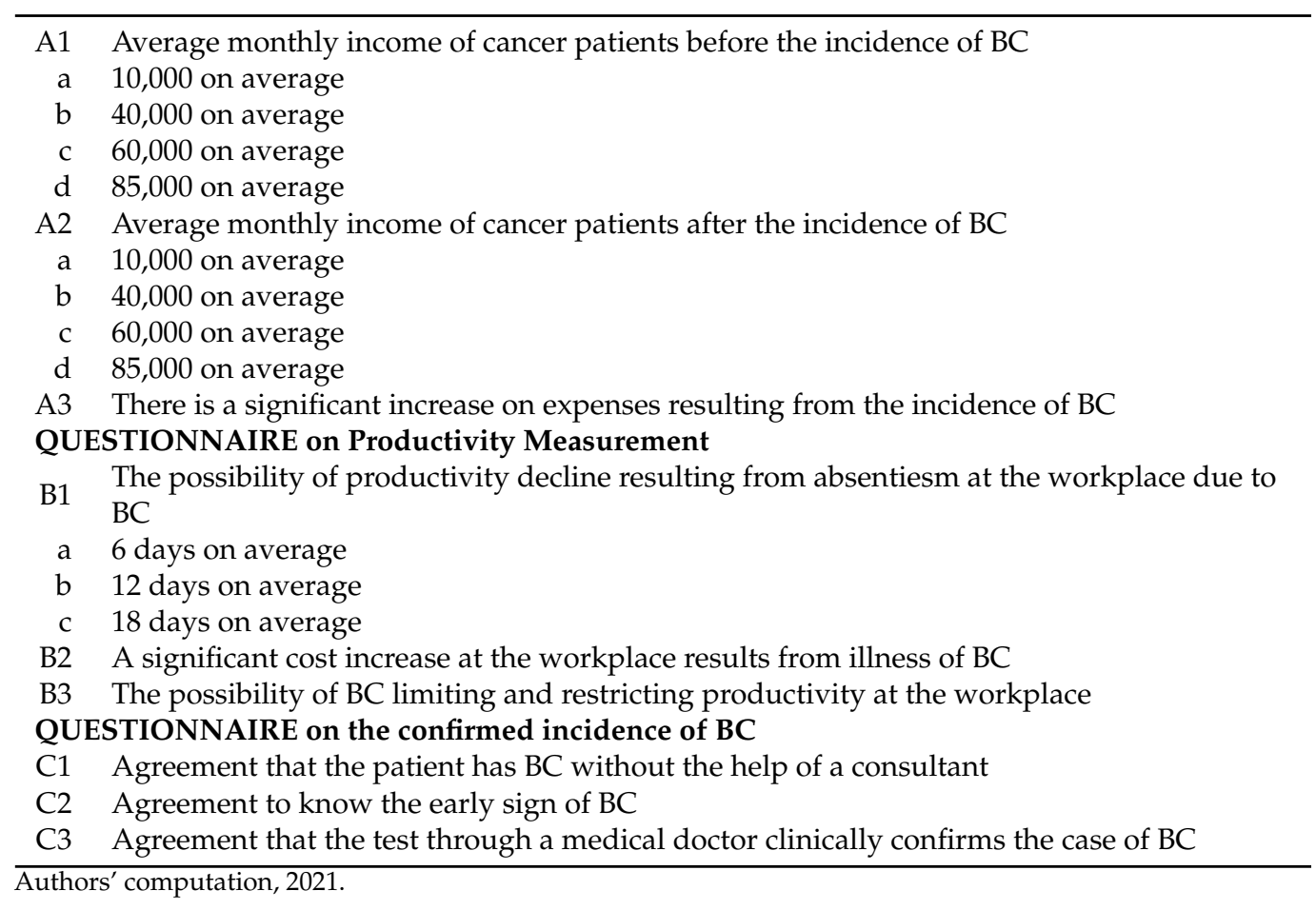

Table A3. Showing Fleiss multi-rater Kappa.

\begin{tabular}{lccccccc}
\hline & \multicolumn{3}{c}{ Overall Agreement } \\
& \multirow{2}{*}{ Kappa } & \multicolumn{3}{c}{ Asymptotic } & & \multicolumn{2}{c}{ Asymptotic 95\% Confidence Interval } \\
\cline { 3 - 8 } & & Standard Error & $\mathbf{z}$ & Sig. & Lower Bound & Upper Bound \\
\hline Overall Agreement & 0.042 & & 0.018 & 2.302 & 0.021 & 0.006 & 0.079 \\
\hline Note: ample data contain $\mathbf{2 0 0}$ useful subjects and nine raters. & & &
\end{tabular}

Authors' computation, 2021.

In rating the general level and the quality of questionnaire administration on breast cancer among women in Southwest Nigeria, the study further conducted Fleish Kappa asymptotic rating over all respondents' responses. The result again is significant at a 5\% level of significance and the coefficient is positive, showing an overall acceptance and satisfaction in the co-movement of the relationship among the coded questionnaires under investigation. For the asymptotic confidence interval, the Kappa value coefficient falls within the lower and upper bound but skews closer to the upper bound margin. Hence, the result further establishes the claim that the financial and income effect of breast cancer is high as indicated by our respondents but with very low productivity effects.

Reliability Test on our data: In this paper, the Cronbach's alpha test was adopted using SPSS to test the consistency of the study questionnaire. Cronbach's alpha is a measure 
of internal consistency, which is, how closely related a set of items are as a group. It is considered to be a measure of scale reliability. A 'high' value for alpha does not imply that the measure is unidimensional.

Cronbach's alpha is thus a function of the number of items in a test, the average covariance between pairs of items, and the total score variance. The resulting coefficient $(\alpha)$ of reliability ranges from 0 to 1 in providing this overall assessment of a measurement's reliability.

Table A4. Cronbach's alpha reliability test result.

\begin{tabular}{cc} 
& Reliability Statistics \\
\hline Cronbach's Alpha & No. of Items \\
\hline 0.600 & 9 \\
\hline Source: Authors' computation, 2021.
\end{tabular}

Table A4 portrays the Cronbach's alpha reliability test result conducted to confirm our questionnaire's consistency and reliability in answering the questions on financial, income, and productivity effects of breast cancer among women in Southwest Nigeria. From the literature, Cronbach's alpha is an instrument of the reliability test with a scale of 1-0 in its estimation. The closer to 1 in its value, the better and fitted. With the result of 0.600 on the Cronbach's alpha scale, we strongly submit that the general responses from our respondents are reliable.

Table A5. Scale: Reliability test. Case Processing Summary.

\begin{tabular}{lccc}
\hline & & No. & $\%$ \\
\hline \multirow{3}{*}{ Cases } & Valid & 200 & 100.0 \\
\cline { 2 - 4 } & Excluded $\left(^{\mathrm{a}}\right)$ & 0 & 0.0 \\
\cline { 2 - 4 } & Total & 210 & 100.0 \\
\hline
\end{tabular}

$\left({ }^{a}\right)$ indicates listwise deletion based on all variables in the procedure.

The case processing summary is yet another test result which reveals that these conclusions are relevant and accepted by the system in estimation. Hence, all the questions interact together to produce the final product with no variable excluded.

\section{References}

Ahmad, Auwal A., Titus Shekarau, Idris Abdullahi Nasir, Zayyad Muhammad Aminu, Shafi'U Muhammad, and Umar Mukhtar Danmusa. 2015. Assessment of costs and burden associated with cancer chemotherapy in patients attending a tertiary hospital in Zaria, Nigeria. Cancer Biology 5: 17-21.

Amin, Said Mohammed, Henry Azuh S. Ewunonu, Emmanuel Oguntebi, and Idris Mohammed Liman. 2017. Breast cancer mortality in a resource-poor country: A 10-year experience in a tertiary institution. Sahel Medical Journal 20: 93. [CrossRef]

Azubuike, Samuel O., Colin Muirhead, Louise Hayes, and Richard McNally. 2018. Rising global burden of breast cancer: The case of sub-Saharan Africa (with emphasis on Nigeria) and implications for regional development: A review. World Journal of Surgical Oncology 16: 1-13. [CrossRef] [PubMed]

Binuomoyo, Olayinka K. 2010. The Nigerian pension system: Reform and expectations. Pensions: An International Journal 15: 3-10. [CrossRef]

Canadian Breast Cancer Network Survey Report. 2010. Breast Cancer: Economic Impact and Labour Force Re-Entry 2010. Available online: https:/ / www.cbcn.ca/en/bc_economic_impact (accessed on 22 October 2020).

Capri, Stefano, and Antonio Russo. 2017. Cost of breast cancer based on real-world data: A cancer registry study in Italy. BMC Health Services Research 17: 84. [CrossRef] [PubMed]

Changik, J. O. 2014. Cost-of-illness studies: Concepts, scopes, and methods. Clinical and Molecular Hepatology, National Library of Medicine, National Center of Biotechnological Information 20: 327. [CrossRef]

Clabaugh, Gerd, and Marcia M. Ward. 2008. Cost-of-illness studies in the United States: A systematic review of methodologies used for direct cost. Value in Health, National Library of Medicine, National Center of Biotechnological Information 11: 13-21. [CrossRef]

Dahlui, Maznah, Sofea Ramli, and Awang M. Bulgiba. 2011. Breast cancer prevention and control programs in Malaysia. Asian Pacific Journal of Cancer Prevention 12: 1631-34. 
De-Silva, S. J. 2016. Work of Women in Nigeria. World Bank Blogs. Available online: https://blogs.worldbank.org/africacan/thework-of-women-in-nigeria (accessed on 22 October 2020).

Ekwueme, Donatus U., Gery P. Guy Jr., Sun Hee Rim, Arica White, Ingrid J. Hall, Temeika L. Fairley, and Hazel D. Dean. 2014. Health and economic impact of breast cancer mortality in young women, 1970-2008. American Journal of Preventive Medicine 46: 71-79. [CrossRef]

Francisci, S., S. Guzzinati, G. Capodaglio, D. Pierannunzio, S. Mallone, A. Tavilla, T. Lopez, S. Busco, W. Mazzucco, C. Angiolini, and et al. 2020. Patterns of care and cost profiles of women with breast cancer in Italy: EPICOST study based on real world data. The European Journal of Health Economics 21: 1003-13. [CrossRef]

Garau, M., K.K. Shah, P. Sharma, and A. Towse. 2015. Is the link between health and wealth considered in decision making? Results from a qualitative study. International Journal of Technology Assessment in Health Care 31: 449-56. [CrossRef] [PubMed]

Gordon, L., P. Scuffham, S. Hayes, and B. Newman. 2007. Exploring the economic impact of breast cancers during the 18 months following diagnosis. Psycho-Oncology: Journal of the Psychological, Social and Behavioral Dimensions of Cancer 16: 1130-39. [CrossRef]

Goeree, R., B.J. O'Brien, G. Blackhouse, K. Agro, and P. Goering. 1999. The valuation of productivity costs due to premature mortality: A comparison of the human-capital and friction-cost methods for schizophrenia. The Canadian Journal of Psychiatry 44: 455-63. [CrossRef] [PubMed]

Jedy-Agba, E., M. P. Curado, O. Ogunbiyi, E. Oga, T. Fabowale, and F. Igbinoba. 2012. Cancer incidence in Nigeria: A report from population-based cancer registries. Cancer Epidemiology 36: e271-78. [CrossRef] [PubMed]

Jefferson, T., V. Demicheli, and M. Mugford. 2000. Cost-of-Illness Studies, Elementary Economic Evaluation in Health Care, 2nd ed. London: BMJ Publishing Group, pp. 17-29.

Johannesson, M., and G. Karlsson. 1997. The friction cost method: A comment. Journal of Health Economics 16: 249-55. [CrossRef]

Johansson, P. O. 1995. Evaluating Health Risks: An Economic Approach. Cambridge: Cambridge University Press.

Kirschstein, R. 2000. Disease-Specific Estimates of Direct and Indirect Costs of Illness and NIH Support: Fiscal Year 2000 Update; Bethesda: National Institutes of Health. Available online: http:/ / ospp.od.nih.gov/ ecostudies/COIreportweb.htm (accessed on 22 October 2020).

Koopmanschap, M. A., F. F. Rutten, B. M. van Ineveld, and L. Van Roijen. 1995. The friction cost method for measuring indirect costs of disease. Journal of Health Economics 14: 171-89. [CrossRef]

Lauzier, S., E. Maunsell, M. Drolet, D. Coyle, N. Hébert-Croteau, J. Brisson, B. Mâsse, B. Abdous, A. Robidoux, and J. Robert. 2008. Wage losses in the year after breast cancer: Extent and determinants among Canadian women. Journal of the National Cancer Institute 100: 321-32. [CrossRef]

Mahmood, H. Z., I. H. Khaliq, Z. Iqbal Bhatti, J. K. Wilson, K.M. Gondal, S. Malik, and S. Zaman. 2018. Household costs of breast cancer morbidity: An empirical assessment from Pakistan, supplement. JBUON 23: S28-S33. [CrossRef]

Matebu, A., and M. Shibabaw. 2015. Partial and Total Productivity Measurement Models for Garment Manufacturing Firms. Jordan Journal of Mechanical \& Industrial Engineering 9: 167-76.

Mincer, J. 1958. Investment in human capital and personal income distribution. Journal of Political Economy 66: 281-302. [CrossRef]

Mustapha, M. I. 2015. Economic Burden of Cancer on Patients Treated at Radiotherapy Department of University College Hospital (Uch). Ibadan: Radiology.

Pauly, M. V. 1995. Valuing health care benefits in money terms. Valuing Health Care: Costs, Benefits, and Effectiveness of Pharmaceuticals and Other Medical Technologies, 99-124.

Slater, H. 2020. Study Finds Metastatic Breast Cancer Causes High Economic Burden through Lost Productivity. Available online: https: / www.cancernetwork.com/view / study-finds-metastatic-breast-cancer-causes-high-economic-burden-throughlost-productivity (accessed on 16 September 2020).

Trogdon, J. G., X. Liu, K. E. Reeder-Hayes, J. Rotter, D. U. Ekwueme, and S. B. Wheeler. 2020. Productivity costs associated with metastatic breast cancer in younger, midlife, and older women. Cancer 126: 4118-25. [CrossRef] [PubMed]

University of Michigan Report. 2014. 25\% of Breast Cancer Survivors Report Financial Decline Due to Treatment. Available online: https:/ / www.rogelcancercenter.org/news/archive/25-breast-cancer-survivors-report-financial-decline-due-treatment (accessed on 22 October 2020).

Veenstra, C. M., L. P. Wallner, R. Jagsi, P. Abrahamse, J. J. Griggs, C. J. Bradley, and S. T. Hawley. 2017. Long-term economic and employment outcomes among partners of women with early-stage breast cancer. Journal of Oncology Practice 13: e916-e926. [CrossRef] [PubMed]

Zainal, N. Z., N. R. Nik-Jaafar, A. Baharudin, Z. A. Sabki, and C. G. Ng. 2013. Prevalence of depression in breast cancer survivors: A systematic review of observational studies. Asian Pacific Journal of Cancer Prevention 14: 2649-56. [CrossRef] [PubMed] 